\title{
Assessing U.S. Drug Problems and Policy A Synthesis of the Evidence to Date
}

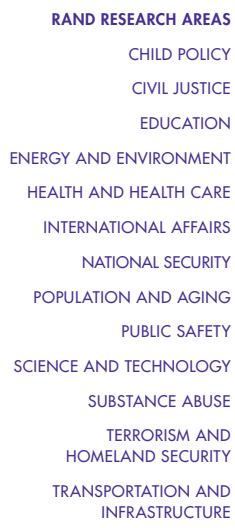

This product is part of the RAND Corporation research brief series. RAND research briefs present policy-oriented summaries of individual published, peer-reviewed documents or of a body of published work.

Corporate Headquarters 1776 Main Street P.O. Box 2138 Santa Monica, California 90407-2138 TEL 310.393 .0411 FAX 310.393 .4818

(C) RAND 2005

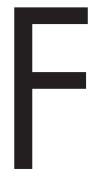
or the past 15 years, the RAND Drug Policy Research Center has been analyzing U.S. drug problems and policy. To synthesize some of the findings of RAND's own research and that of others, RAND has produced a concise Occasional Paper, How Goes the "War on Drugs"? An Assessment of U.S. Drug Problems and Policy. This research brief summarizes that assessment and its recommendations for future policy.

\section{How Successful Has the War on Drugs Been?}

To answer this question, we first ask, successful at achieving what goals? The current national drug control strategy is not primarily directed toward reducing the consequences of drug use, such as overdoses and HIV infection. The only explicit goals are related to reducing drug use itself.

In that regard, the drug war has had a mixed record, at least superficially. The percentage of the population reporting past-month use of some illicit drug declined by half between 1985 and 1992 .

Since then, however, drug use by that measure is up by about a third. Furthermore, current use of marijuana by teenagers increased substantially in the mid to late 1990s; in 2003, 21 percent of 12thgraders reported having used marijuana or hashish within the previous month.

We say "superficially" because trends in drug use are not determined solely by government policy. National trends are an aggregation of individual use patterns, which are influenced by a variety of factors.

Most users of any drug begin in their teen or young adult years. The strongest influence on initiation is typically use by friends or family, although prior alcohol and tobacco use, along with genetic factors, may also play a role. Use of marijuana is associated with subsequent use of harder drugs, although causal connections are not firmly established.

\section{Abstract}

The RAND Drug Policy Research Center has published an Occasional Paper offering a concise, accessible, objective view of where the United States has been, now stands, and might go in the future in its long "war on drugs." The authors assess the success of drug policies to date and review possible reasons why they have not been more successful. They recommend management of the drug problem for the long term, use of different policy levers depending on the stage of the epidemic, and tolerance of cross-state policy variation.

The course of drug use plays out differently in different people. Most people who try a drug use it only experimentally or moderately. Some people, however, become dependent; the proportion varies by drug — 23 percent for heroin, 17 percent for cocaine, 9 percent for marijuana. It is these dependent users who account for most of the burden on society. They are the most likely to require health care services because of their drug use and are the primary source of drug market revenues because they use much longer and more intensively.

Because drug use is spread mainly through social contacts, patterns of drug use over time can have some of the characteristics of a contagious epidemic. Early users of a new drug lure other users, who lure still others. The burgeoning initiation rate falls abruptly as the drug's ill effects become apparent. That leaves many users who have become dependent during the upswing; they will gradually stop using over the course of many years.

The use of most drugs thus waxes and wanes, control policies notwithstanding. Therefore, while specific use-reduction targets represent laudable 
objectives, they may be very easy or very difficult to achieve, depending on factors largely outside the government's control.

\section{Why Hasn't the Drug War Been a Greater Success?}

Given the uncertainties in arriving at any assessment, it is difficult to convincingly assert the success of U.S. drug policy to date. What factors within the government's control may have contributed to shortfalls?

First, the balance among enforcement, treatment, and prevention has probably not been optimal. The drug control budget goes mostly to enforcement, and some studies suggest that a marginal reallocation toward treating heavy drug users would have been more effective in reducing drug consumption and drug-related crime and other consequences. Enforcement is problematic when used against well-established drug markets because they are supplied by diffuse networks and arrested sellers are easily replaced. Treatment also has its limitations, however. It cannot solve immediate problems, like an increase in drug sales down the street, the way enforcement can. Its benefits accumulate slowly. However, treatment is cheaper than enforcement and attacks demand directly; it also does not have the ill effects of enforcement, e.g., racial disparities in who bears enforcement's burden. It is less clear that the government would have achieved dramatically more by shifting funds from enforcement to prevention. As with treatment, the benefits of prevention accumulate slowly, and even model programs appear to be cost-effective in no small part because they are relatively cheap, not because they eliminate more than a modest fraction of use. School-based prevention programs do, however, have beneficial effects on use of other substances (alcohol and tobacco) and on other behaviors.

Second, the balance among enforcement strategies may not have been optimal. RAND researchers have shown that cocaine consumption might have been further reduced if some of the money spent trying to control cocaine in source countries or in transit had been spent on enforcement within the United States. Also, long sentences for sellers in the United States might have been focused more effectively on the most culpable distributors.

\section{How Should U.S. Drug Policies Evolve?}

While the Occasional Paper is intended as a source of information and analysis, not a detailed set of policy prescriptions, the authors draw some broad principles out of their analytic perspective.

- Manage this long-term problem for the long term. The drug problem is not going away. It must be managed so as to limit the number of people who use, the frequency or duration of their use, and the damage they do to themselves and others, together with the damage resulting from policy choices.

- Use all policy levers. All approaches should be considered in formulating the right policy mix for the situation. In particular, the mix of control strategies should be timed to the epidemic cycle. In early epidemic stages, dealers are not numerous and enforcement may be effective. In the later stages, when the burdens of heavy use are taking a social toll, and when the market has become too large and diffuse for enforcement to disrupt, the balance should shift to treatment. Prevention of the next epidemic should always be under way.

- Draw strength from cross-state variations in drug policy. The federal government has sought to rein in those few states whose policies have deviated from its own. The government might instead tolerate and seek to learn from state variations that do not seriously undermine the intent of the federal strategy.

- Press for a more dispassionate debate. Discussion of policy alternatives has been marked by polemics from both sides. The public should demand that the parties to the debate attend to the apparent or likely effects of current or alternative policies. They should demand as much information on effects as they are now getting on the policies' consistency with the moral scruples of the discussants.

\footnotetext{
This research brief summarizes work done for the RAND Drug Policy Research Center, a joint endeavor within RAND Health and RAND Infrastructure, Safety, and Environment and documented in How Goes the "War on Drugs"? An Assessment of U.S. Drug Problems and Policy by Jonathan P. Caulkins, Peter Reuter, Martin Y. Iguchi, and James Chiesa, OP-121DPRC (available at http://www.rand.org/publications/OP/OP121), 2005, 61 pp., \$14, ISBN: 0-8330-3737-4. OP-121 is also available from RAND Distribution Services (phone: 310.451.7002; toll free: 877.584.8642; or email: order @ rand.org). The RAND Corporation is a nonprofit research organization providing objective analysis and effective solutions that address the challenges facing the public and private sectors around the world. RAND's publications do not necessarily reflect the opinions of its research clients and sponsors. RAND ${ }^{\circledR}$ is a registered trademark.
}

RAND Offices Santa Monica • Washington - Pittsburgh • New York • Doha • Berlin • Cambridge • Leiden 
A JOINT ENDEAVOR WITHIN RAND HEALTH AND

RAND INFRASTRUCTURE, SAFETY, AND ENVIRONMENT

CHILD POLICY

CIVIL JUSTICE

EDUCATION

ENERGY AND ENVIRONMENT

HEALTH AND HEALTH CARE

INTERNATIONAL AFFAIRS

NATIONAL SECURITY

POPULATION AND AGING

PUBLIC SAFETY

SCIENCE AND TECHNOLOGY

SUBSTANCE ABUSE

TERRORISM AND HOMELAND SECURITY

TRANSPORTATION AND INFRASTRUCTURE
This PDF document was made available from www.rand.org as a public service of the RAND Corporation.

This product is part of the RAND Corporation research brief series. RAND research briefs present policy-oriented summaries of individual published, peerreviewed documents or of a body of published work.

The RAND Corporation is a nonprofit research organization providing objective analysis and effective solutions that address the challenges facing the public and private sectors around the world.

\section{Support RAND}

Browse Books \& Publications

Make a charitable contribution

For More Information

Visit RAND at www.rand.org

Explore RAND Drug Policy Research Center

View document details
Limited Electronic Distribution Rights

This document and trademark(s) contained herein are protected by law as indicated in a notice appearing later in this work. This electronic representation of RAND intellectual property is provided for non-commercial use only. Permission is required from RAND to reproduce, or reuse in another form, any of our research documents for commercial use. 